\title{
Capítulo 4 - 0 processo criativo de Ampère na elaboração da eletrodinâmica
}

\author{
Ivã Gurgel
}

\section{SciELO Books / SciELO Livros / SciELO Libros}

GURGEL, I. O processo criativo de Ampère na elaboração da eletrodinâmica. In: MOURA, B. A., and FORATO, T. C. M., comps. Histórias das ciências, epistemologia, gênero e arte: ensaios para a formação de professores [online]. São Bernardo do Campo, SP: Editora UFABC, 2017, pp. 71-92. ISBN 978-85-68576-84-7. https://doi.org/10.7476/9788568576847.0005.

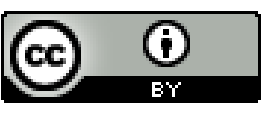

All the contents of this work, except where otherwise noted, is licensed under a Creative Commons Attribution 4.0 International license.

Todo o conteúdo deste trabalho, exceto quando houver ressalva, é publicado sob a licença Creative Commons Atribição $\underline{4.0}$.

Todo el contenido de esta obra, excepto donde se indique lo contrario, está bajo licencia de la licencia $\underline{\text { Creative }}$ Commons Reconocimento 4.0. 


\section{O PROCESSO CRIATIVO DE AMPÈRE NA ELABORAÇÃO DA ELETRODINÂMICA'}

Ivã Gurgel

\section{Sobre a criação nas ciências}

Como são elaborados conceitos, leis e teorias das ciências? Esta questão guarda uma complexidade grande, fazendo com que diferentes cientistas, filósofos e historiadores tenham se dedicado a ela, constituindo uma rica diversidade de posicionamentos.

Uma linha de pensamento que ganhou grande repercussão ao longo dos tempos foi a tradição que podemos denominar simplificadamente de empírico-indutivista. Ela nos remete a autores de diferentes épocas, como Francis Bacon (1561-1626), e consiste na afirmação de que, por um processo sistemático de observação de fatos, se possível controlado por experimentação, poder-se-ia obter leis gerais sobre a natureza. Assim, podemos

\footnotetext{
1 Este capítulo se baseia em parte da tese de doutorado do autor (GURGEL, 2010). Ele agradece à Profa. Christine Blondel pelo forte apoio no início de seus estudos sobre o tema. Uma das obras dela (1982) é referência importante neste texto.
} 
apontar alguns pressupostos empírico-indutivistas nos seguintes termos (ZANETIC; MOZENA, 2012):

- Há, em uma boa medida, uma objetividade nas observações realizadas e as mesmas podem ser repetidas/ reproduzidas.

- É possível estabelecer bons procedimentos que delimitem a ocorrência ou não de fatos (ou seja, é possível realizar uma experimentação devidamente controlada).

- É possível propor leis gerais a partir das observações e experimentações.

Nessa perspectiva filosófica, os conceitos e leis não seriam nada muito além de uma coleção de fatos devidamente verificados (MILL, 1843/1978). Esse posicionamento fica claro na obra do filósofo John Stuart-Mill (1806-1873). Em uma passagem de seu livro Sistema de Lógica Indutiva e Dedutiva (1843), na qual disserta sobre a proposição de Johannes Kepler (15711630), o qual afirma que as órbitas dos planetas são elípticas, o autor aponta que "[...] a elipse estava nos fatos antes que [Kepler] a reconhecesse [...]. Kepler não colocou o que concebera nos fatos, mas viu isso neles" (MILL, 1843/1978, p. 134).

A passagem anterior indica que, nas concepções empírico-indutivistas, a produção do conhecimento não exige (e até mesmo deve evitar) interpretações que envolvam um modo de olhar específico dos sujeitos. Contudo, essa filosofia passou por diferentes críticas em sua própria época e em décadas posteriores. De modo geral, ainda que objetividade, observação e experimentação controlada sejam aspectos fundamentais da ciência, buscou-se apontar que a interpretação dos fatos é, também, carregada de teoria, sendo até mesmo inseparável o dado de sua interpretação (HANSON, 1974). 
Mesmo que os posicionamentos estritamente empírico-indutivistas tenham sido criticados no âmbito filosófico, muitas pesquisas demonstram que seus pressupostos ainda são muito presentes nos contextos educacionais (GIL-PÉREZ et al., 2001). Mesmo que professores não defendam essa visão de ciência explicitamente, ela acaba estando presente em suas posturas ao buscarem ensinar ciências. Quando, por exemplo, levamos uma atividade experimental para a sala de aula e não valorizamos o trabalho investigativo e interpretativo dos alunos, estamos implicitamente considerando que "a experiência fala por si mesma".

O objetivo deste capítulo é dar uma contribuição teórica para esta questão, analisando um caso histórico: a criação da eletrodinâmica por André-Marie Ampère (1775-1836). Partindo de uma experiência realizada por Hans Christian Oersted (17771851), Ampère criou um novo arcabouço conceitual que levou muitos cientistas da época a uma reinterpretação de todo um conjunto de fenômenos elétricos e magnéticos.

Em termos atuais, a experiência de Oersted consiste no alinhamento de uma agulha imantada (como a de uma bússola) com o campo magnético produzido pela corrente elétrica gerada em um fio condutor. A partir dela, houve a unificação da eletricidade com o magnetismo, áreas que ainda se encontravam independentes. Na próxima seção do texto, será feito um resgate do trabalho de Oersted e de alguns de seus antecedentes para, em seguida, constituir uma narrativa sobre a obra de Ampère.

\section{Alguns antecedentes à eletrodinâmica de Ampère}

Os efeitos de atração e repulsão característicos da eletricidade e do magnetismo são conhecidos desde a Antiguidade. 
Deste período até a metade do século XVIII, uma grande quantidade de conhecimento foi adquirida sobre esses fenômenos, mas o saber era tratado de forma bastante dispersa, não constituindo com clareza uma unidade de análise (BLONDEL, 1982).

Um pensador que contribuiu para os estudos sobre a eletricidade e o magnetismo foi Benjamin Franklin (1706-1790) (AUDOUZE, 2006). Seu trabalho experimental se tornou bastante conhecido, principalmente por ter estudado a natureza dos raios que ocorrem durante as tempestades como fenômenos de descargas elétricas e pelas experiências com descargas elétricas produzidas por garrafas de Leyden. No entanto, para a finalidade deste trabalho, interessa verificar como ele interpreta a relação entre eletricidade e magnetismo.

Por volta de 1750, Franklin realiza uma série de experiências e, em seus relatos, descreve a imantação de agulhas através de descargas elétricas, o que indicava uma associação entre eletricidade e magnetismo (MARTINS, 1986). Contudo, como os mesmos efeitos poderiam ser produzidos por outros processos, associados ao aquecimento da agulha, Franklin é levado a considerar que as descargas elétricas são apenas auxiliares no processo de imantação. Anos depois, em uma carta, ele declara: "Em relação ao magnetismo, que parece ser produzido pela eletricidade, minha opinião real é que esses dois poderes da natureza não possuem afinidade mútua, e que a aparente produção do magnetismo é puramente acidental" (FRANKLIN, 1773 apud MARTINS, 1986, p. 7).

A posição de Franklin pode ser considerada como bastante representativa para seu período histórico e para algumas décadas subsequentes. Podemos afirmar que, naquela época, muitos filósofos naturais acreditavam em uma relação entre eletricidade e magnetismo, mas a falta de base tanto teórica quanto 
empírica para a compreensão desta relação fazia com que ela fosse descartada.

A natureza dos fenômenos elétricos e magnéticos muitas vezes se apresenta de modo muito díspar. Por exemplo, enquanto a atração e repulsão de ímãs são, em geral, fenômenos de baixa intensidade e que perduram no tempo, as descargas elétricas são o oposto, algo muito localizado no tempo e de uma intensidade até mesmo violenta. René Haüy (1743-1822), em seu Traite Élémentaire de Physique (Tratado Elementar de Física), apresenta bem essa distinção, afirmando que "[...] a eletricidade se manifesta aos olhos por jatos de luz, por faíscas estridentes, o magnetismo age passivamente e em silêncio" (HAÜY, $1821 / 1855$, p. 125 , tradução nossa).

Isso faz com que nas primeiras pesquisas com pilhas, os fenômenos que os filósofos naturais buscavam observar, fossem da mesma natureza que as descargas elétricas. Assim, em 1820, quando Oersted realiza sua experiência, buscar um efeito contínuo da eletricidade em um condutor e associá-lo ao magnetismo não eram hipóteses evidentes.

O dinamarquês Hans Christian Oersted obteve uma sólida formação em ciências e filosofia. Inserindo-se dentro da Naturphilosophie germânica. Oersted irá acreditar em uma unidade natural, em que todas as manifestações físicas (térmicas, elétricas, magnéticas, óticas) deveriam ser explicadas por um mesmo princípio. Ele mesmo declara, em um artigo da Enciclopédia de Edimburgo, que foram razões filosóficas que o guiaram à sua descoberta do eletromagnetismo (MARTINS, 1986).

Nos primeiros anos do século XIX, isto é, logo após a invenção da pilha por Alessandro Volta (1745-1827), Oersted começa a fazer suas primeiras experiências com pilhas. No entanto, é somente no inverno de 1819-1820 que Oersted realiza 
sua descoberta. Nesse momento, ele ministra um curso na Universidade de Copenhagen em que discutia suas ideias sobre a unidade das forças da natureza. De acordo com sua declaração, ele afirma que também realizava pesquisas buscando verificar os efeitos de um circuito fechado sobre uma agulha imantada. No entanto, foi durante uma aula que ministrava na Universidade de Copenhagen que ele pôde verificar que, caso a agulha fosse colocada paralelamente ao fio condutor, esta era desviada, formando um ângulo de inclinação em relação à direção do mesmo fio. Após essa primeira descoberta, Oersted busca fazer experiências detalhadas nas quais tem por objetivo compreender a natureza dessa interação. Em julho de 1820, escreve um artigo intitulado Experimenta Circa Effectum Conflitus Electrici in acum Magneticam (Sobre o Experimento do Efeito do Conflito Elétrico sobre a Agulha Magnética), em que apresenta suas experiências e procura explicar suas causas.

Oersted é um adepto de uma das interpretações vigentes em sua época e considera a existência de dois tipos de fluídos elétricos, um positivo e outro negativo. Ele julga que, quando o fio é ligado à pilha, ocorre o movimento de ambos os fluídos internamente ao fio. Devido à carga que cada um porta, os fluídos devem realizar, no fio condutor, trajetórias em sentidos contrários. Esse encontro provoca a interação entre ambos, o que Oersted chama de conflito elétrico, e dá aos fluídos um movimento de rotação (como um redemoinho). Além disso, o autor postula que este conflito não se limitará à região interna ao fio, mas que se estenderá à região de seu entorno. Em seu texto original, após uma exposição detalhada dos efeitos provocados em uma agulha em diferentes pontos do espaço ao redor do fio, o autor conclui: 
Examinemos brevemente qual é, após todos esses fatos, a ideia que nós podemos fazer do fenômeno. O conflito elétrico só age sobre as partículas magnéticas da matéria. Todos os corpos não magnéticos são permeáveis ao conflito elétrico, mas os corpos magnéticos, ou, para melhor dizer, as partículas magnéticas desses corpos, opõem uma resistência à passagem desse conflito, de maneira a acabarem levadas no choque das ações contrárias.

Parece, após os fatos expostos, que o conflito elétrico não é circunscrito ao fio condutor, mas que ele tem ao torno dele uma esfera de atividade que se estende muito. (OERSTED, 1820/1986, p. 118)

Podemos dar destaque a um conjunto de elementos presentes no processo criativo de Oersted. Primeiramente, vale lembrar, suas motivações iniciais vinham de uma visão filosófica de mundo e pouco dependiam de fatos mais evidentes. Pelo contrário, caso tivesse se limitado às experiências mais conhecidas, dificilmente teria chegado à experiência que leva seu nome. Outro ponto interessante de notar é que a experiência traz um padrão de comportamento empírico bastante novo. Neste momento, não se espera uma interação que indicasse uma "dinâmica circular" ao redor do fio. Para explicar a mesma, Oersted retoma a ideia de vórtices, que nos remete a autores mecanicistas, trazendo uma interpretação criativa aos fenômenos observados.

O texto de Oersted se popularizou relativamente rápido para os padrões da Europa do século XIX. Contudo, poucos pensadores adotaram sua interpretação para o fenômeno observado. Filósofos naturais e posteriormente os cientistas que se dedicavam a assuntos da mesma natureza, como Jöns Jacob Berzelius (1779-1848), Johann Joseph Ritter von Prechtl (17781854) e William Hyde Wollaston (1766-1828), tenderam a interpretar o fenômeno como uma magnetização do fio condutor, 
visto que o mesmo passaria a admitir polos magnéticos ao longo de seu comprimento.

Outra interpretação será constituída nos trabalhos de Ampère. Na próxima seção, será exposto com mais detalhamento seu processo criativo.

\section{Ampère e a criação da eletrodinâmica}

André-Marie Ampère adquire, desde sua juventude, uma sólida formação, mesmo não tendo seguido os meios formais de instrução. Nesse período, ele tem contato com obras como a Mécanique, de Lagrange, e a Encyplopédie, de Diderot e d'Alembert, que representam bem o conhecimento adquirido em sua época (LOCQUENEUX, 2008). Além da formação científica, Ampère se interessa profundamente por diversas áreas, passando pela filosofia e as letras. Em 1797, ele deixa sua pequena cidade natal e parte a Lyon, onde estabelece contato com intelectuais da região e estuda, em particular, a obra de Lavoisier (HOFMANN, 1995). Nesse momento, ele inicia mais profundamente suas reflexões filosóficas e funda uma sociedade com amigos, na qual se discute questões metafísicas. Como Oersted, é influenciado pela corrente germânica que considera a existência de uma unidade na natureza (BLONDEL, 1982).

Em 1800, é eleito para a academia de ciências de Lyon, assistindo lá, no ano seguinte, uma apresentação feita por Volta sobre sua pilha. Nessa mesma sessão, Ampère começa a leitura de um mémoire ${ }^{2}$ sobre eletricidade e magnetismo, mas a leitura

\footnotetext{
2 Um mémoire consiste em um manuscrito submetido à academia para ser lido em uma de suas seções.
} 
desse manuscrito nunca acabou. O que nos resta é a introdução escrita por ele, que traz elementos importantes das primeiras etapas de seu pensamento sobre estes fenômenos.

Inicialmente, Ampère relata que grandes descobertas, como as feitas por Newton, têm a característica de explicar uma gama grande de fenômenos, muitos deles que não seriam esperados inicialmente. Após essa breve ressalva, ele irá considerar:

Eu pude me lisonjear que o acaso me havia favorecido de uma dessas ideias que abrem aos físicos uma carreira nova, logo após ter reduzido todos os fenômenos do ímã e da eletricidade a um princípio único, eu vi nascer desses princípios as explicações as mais simples e as mais naturais de um grande número de fatos cujas causas ainda eram ignoradas. (AMPÈRE,1801/1982, p. 1, tradução nossa)

Com isso, ele anuncia seu projeto de unificação entre eletricidade e magnetismo, que difere completamente do seu trabalho posterior. No entanto, é interessante notar que, desde suas primeiras pesquisas, o autor era guiado por uma perspectiva que buscava estabelecer essa unificação.

Talvez o elemento mais curioso apresentado neste manuscrito inacabado seja a negação da ação à distância para os efeitos elétricos, concepção vigente na época devido aos trabalhos com a Lei de Coulomb. Ampère irá considerar que não é por "estarmos habituados", após Newton, a compreender as interações a partir de forças que atuam à distância, que essa consideração deveria ser levada para todos os fenômenos. Para ele, deve existir uma interação que seja explicada pelas próprias características dos fluídos, e com isso ela deve ser contígua no espaço. Como conclusão às suas afirmações preliminares ele estabelece: 
1 - Nós só devemos atribuir aos fluidos elétricos e magnéticos as propriedades observadas em outros fluidos, como a elasticidade comum a todos os gases e a propriedade de aderir aos outros corpos, que nós observamos na maior parte dos líquidos.

2 - Nós não devemos supor nenhuma ação entre os mesmos e os corpos que eles não tocam ou as porções de fluido homogêneo que não lhe são contíguas, a não ser que seja produzido por uma reação do fluido espalhado no espaço intermediário, de onde se segue que nós devemos nos ocupar unicamente da ação de cada molécula de matéria sobre aquelas que estão imediatamente no mesmo ambiente. E como não há ponto de vazio real em torno de nosso globo, essa ação se propagando de ponto a ponto é suficiente para explicar, assim como nós veremos, todos os fenômenos que fazem parte dessa teoria a qual nós poderemos fazer, no futuro, um ramo da mecânica como nós fizemos com a hidrostática, mesmo que esta última ciência tenha sido durante muito tempo uma teoria experimental. (AMPÈRE, 1801/1982, p. 1, tradução nossa)

Considerando que os fluídos têm propriedades próprias que nos permitem explicar a interação entre dois corpos, Ampère busca fundar os fenômenos elétricos e magnéticos na mecânica dos fluídos. No entanto, não deixa de ser interessante considerar que, desde sua juventude, Ampère já estabelece essa busca.

Em 1804, Ampère parte a Paris onde se estabelece até o fim de sua vida. Em 1807, ele é eleito membro da academia de ciências, sobretudo por seus trabalhos de matemática, e ocupa a cadeira deixada por Lagrange. Em 11 de setembro de 1820, François Arago repete as experiências da ação do fio condutor sobre a agulha, realizadas por Oersted. Com isso, Ampère abre uma nova fase de pesquisas e vê claramente a possibilidade de 
fundar uma nova ciência, seu projeto de juventude. Uma carta ao seu filho, datada de 19 de setembro, relata bem seu entusiasmo:

Depois que eu ouvi falar pela primeira vez da bela descoberta do Sr. Oersted, professor em Copenhague, sobre a ação das correntes galvânicas sobre a agulha magnetizada, eu pensei nela continuamente e eu não fiz nada além de escrever uma grande teoria sobre esses fenômenos e todos aqueles já conhecidos sobre o ímã, e não deixei de tentar realizar experiências indicadas por esta teoria. Todas elas tiveram êxito e elas me fizeram conhecer novos fatos. (AMPÈRE, 1820 apud BLONDEL, 1982, p. 45, tradução nossa).

Ampère inicia uma fase de intensa pesquisa que compreende o período de 18 de setembro de 1820 a 15 de janeiro de 1821. Nesse período, ele realiza nove leituras na Academia de Ciências. Um elemento curioso é que Ampère anuncia todas as suas conclusões já na primeira leitura, uma semana após ele ver a demonstração da experiência de Oersted realizada por Arago. Nela, afirma ter feito experiências que comprovariam suas conclusões. Todavia, suas descrições dessas experiências são muito vagas, e nenhum dado conclusivo é apresentado. Dois anos depois, quando publica uma coletânea das leituras realizadas nesse período, Ampère admite que, na primeira delas, do dia 18 de setembro de 1820 e que será nosso objeto do estudo, ainda não havia realizado as experiências, mas somente pensado em como elas seriam (AMPÈRE, 1822). Assim, as experiências somente foram realizadas posteriormente, sendo apresentadas paulatinamente nas leituras dos dias 6, 16 e 30 de outubro e 6 e 13 de novembro, onde os resultados efetivamente aparecem.

Aqui temos um ótimo exemplo de quanto o trabalho de criação, apesar de se referir à realidade e nela se basear, vai 
além do que um dado objetivo ou sistemático permite. Apenas com as indicações dadas pela experiência de Oersted, Ampère constrói um novo corpus explicativo que, a posteriori, explica certos dados que são obtidos através de um grupo de experiências por ele realizadas.

O primeiro mémoire lido por Ampère é, do ponto de vista de processos criativos, o mais interessante. Seu esforço inicial é focado na possibilidade de criarmos novas condições de pensarmos os fenômenos e, durante este processo, o autor já antecipa em sua mente muitos resultados, que comporão sua argumentação. Apesar disso tudo, Ampère anuncia seu projeto da seguinte maneira:

As experiências que eu fiz sobre a ação mútua dos condutores que estão em comunicação com as extremidades de uma pilha voltaica me mostraram que todos os fatos relativos a esta ação podem ser reduzidos a dois resultados gerais, que nós devemos considerar de início como unicamente dados pela observação, ao esperar que nós pudéssemos os levar a um princípio único, ao determinar a natureza e, se possível, a expressão analítica da força que os produz. Eu começarei por enunciá-los sob a forma que me parece a mais simples e a mais geral. (AMPÈRE, 1820/1885, p. 48-49, tradução nossa)

Um primeiro elemento importante em relação ao conteúdo da citação anterior é a consideração que há uma ação mútua entre dois condutores. Aqui ele antecipa sutilmente suas conclusões e reorienta o cenário de investigação das interações entre ímãs e correntes elétricas, para uma relação entre correntes elétricas. Em muitas passagens, Ampère insiste bastante nessa afirmação. Podemos considerá-la como fundamental para seu projeto de unificação, pois, se as ações de 
diversos fenômenos devem ser reduzidas a uma mesma causa, estas devem ser mútuas, mesmo quando consideramos corpus que, a princípio, parecem ter naturezas diferentes. Este é o ponto que o autor buscará chegar. Logo em seguida, ele apresenta o primeiro dos dois resultados gerais:

Ação diretiva. Quando um ímã e um condutor agem um sobre o outro, e no caso em que um deles estando fixo, o outro só pode girar no plano perpendicular à mais curta distância do condutor e do eixo do ímã, aquele que é móvel tende a se mover, de maneira que as direções do condutor e do eixo do ímã formem um anglo reto, e que o polo do ímã que aponta habitualmente o norte esteja à direta disso que nós chamamos comumente a corrente galvânica, denominação que eu creio dever mudar para a de corrente elétrica, e o polo oposto a sua direita, e a linha que mede a mais curta distância do condutor e o eixo do ímã reencontra a direção desse eixo entre os dois polos. (AMPÈRE, 1820/1885, p. 49-50, tradução nossa)

Este resultado pode parecer, a princípio, apenas uma repetição do que Oersted já havia afirmado anteriormente, quando mostrava o desvio da agulha da bússola pelo fio ligado à bateria. No entanto, Ampère considera que a experiência de Oersted não deixa isso claro por misturar efeitos produzidos pela corrente elétrica com os do próprio campo magnético da Terra. Para superar esta limitação, propõe um instrumento no qual a agulha pode ser disposta em um plano vertical e perpendicular ao meridiano magnético da Terra, podendo, assim, evitar os efeitos do próprio campo terrestre. Esse resultado preciso é importante para Ampère por destacar que o ângulo formado é exatamente reto, algo que o postular que duas correntes ficam sempre paralelas. Ele concluirá que nos ímãs há correntes 
internas que são perpendiculares aos seus polos. Assim, uma agulha fica perpendicular ao fio, pois suas correntes internas estão paralelas ao mesmo. Seguindo ainda essa ideia, o autor indica que as ações são mútuas, mesmo se tratando da interação do fio com o ímã. Com isso, Ampère parte de um resultado já aceito, o desvio da agulha, para começar sua argumentação que envolverá várias dimensões desse conjunto de fenômenos.

Ainda nesse extrato, temos um elemento importante. A ideia de corrente elétrica como um movimento organizado e contínuo da eletricidade não existia. Como o projeto de Ampère é o de reduzir todos os fenômenos magnéticos à interação entre correntes, é somente neste contexto que a própria ideia de corrente se estabelece. $\mathrm{O}$ segundo resultado geral apresentado por Ampère é enunciado da seguinte forma:

Ação atrativa ou repulsiva. Esse segundo resultado geral consiste, $1^{\circ}$ no que um condutor tem suas pontas juntas às duas extremidades de uma pilha voltaica, e um ímã cujo eixo faz um ângulo reto com a direção da corrente que ocorre neste condutor conformemente às definições precedentes, se atraem quando o polo austral está à esquerda da corrente que age sobre ele, quer dizer, quando a posição é aquela que o condutor e o ímã tendem a tomar em virtude de sua ação mútua, e se repelem quando o polo austral do ímã está à direta da corrente, quer dizer, quando o condutor e o ímã são mantidos na posição oposta àquela que eles tendem a se colocar mutuamente. (AMPÈRE, 1820/1885, p. 51-52, tradução nossa)

Com isso, o autor estabelece um novo efeito que não havia sido observado. Podemos afirmar que este segundo princípio será a base de toda formulação matemática feita por Ampère 
posteriormente. Para fundamentá-lo, ele apresenta uma experiência na qual uma agulha era disposta verticalmente, tendo um de seus polos localizados na mesma altura de um fio condutor horizontal. Com este instrumento, o autor afirma ter produzido atrações e repulsões, de acordo com o sentido da corrente produzida no condutor.

Logo após o anúncio de seu segundo resultado geral, Ampère reafirma a importância de reciprocidade dos efeitos e busca ressaltar o caráter de unidade estabelecido por eles. Neste mesmo mémoire, ele ainda declara que os mesmos efeitos produzidos pela corrente elétrica no condutor eram produzidos pela própria pilha. Isto traz mais um caráter inovador na sua obra, pois, nessa época, não era óbvio imaginar que os fluídos galvânicos tinham as mesmas propriedades dos fluídos elétricos. Ele estabelece que internamente às pilhas também há a produção de corrente elétrica. Esse fato, mesmo sendo uma constatação indireta, ajuda a corroborar seu projeto de busca de uma causa única (neste caso, a existência de correntes elétricas) como explicação de todos os fenômenos eletromagnéticos. Baseando-se nessas formulações, Ampère irá "concluir" que a causa do magnetismo terrestre é a existência de correntes elétricas na Terra.

[...] a ideia mais simples, e aquela que se apresenta imediatamente a aquele que gostaria de explicar esta direção constante da agulha, não seria ela de admitir na Terra uma corrente elétrica, em uma direção tal que o norte se acharia à esquerda de um homem que, deitado sobre a superfície para ter a face virada do lado da agulha, receberia essa corrente na direção dos seus pés à sua cabeça, de onde concluímos que ela ocorre de leste a oeste, em uma direção 
perpendicular ao meridiano magnético? (AMPÈRE, 1820/1885, p. 55-56, tradução nossa)

Nesse momento, ele define o que hoje chamamos de "observador de Ampère". A imagem a seguir vem de um de seus manuscritos:

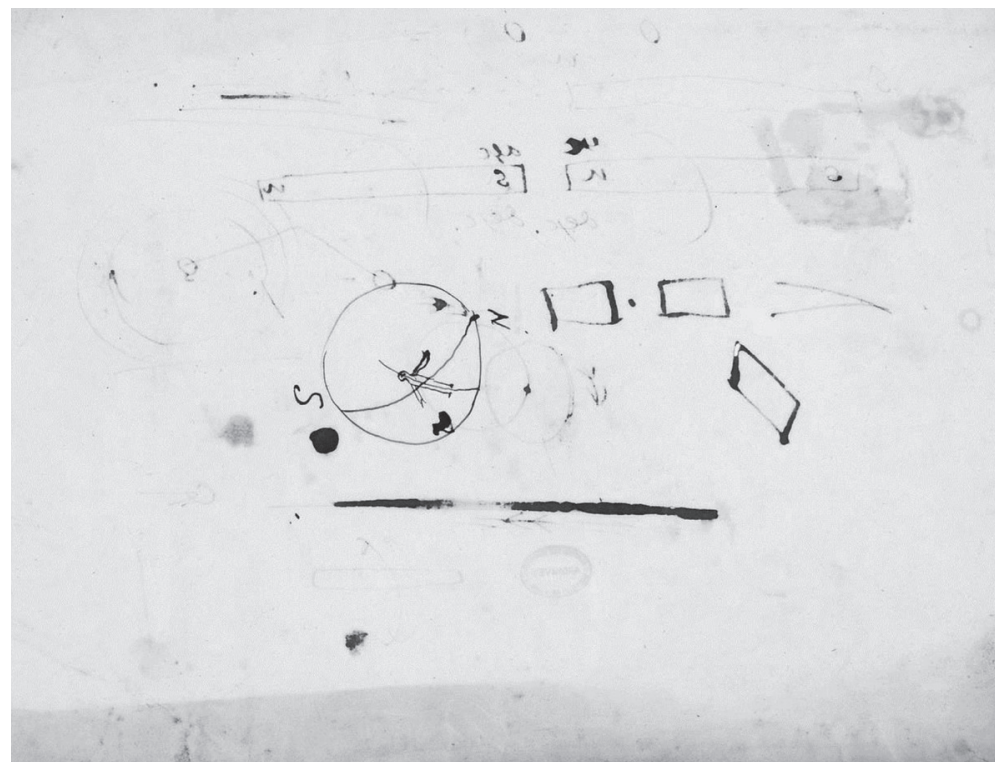

Figura 1 - Le "bonhomme d'Ampère" Fonte: Ampère (1820/2005).

A direção estabelecida para corrente é a mesma para a qual ele pode verificar em suas experiências. Após essa, afirmação ele explorará a possibilidade de um arranjo mais ou menos aleatório de metais poder produzir correntes internamente à Terra. Ele sugere que não é pelo fato que na disposição de uma pilha, com placas de cobre e zinco, esses efeitos sejam intensificados, que deveríamos considerar impossível a formação de 
correntes por outros metais os quais, no caso da Terra, têm a vantagem de se acumular por todo o seu perímetro. Ampère ainda buscará partir da existência de correntes na Terra para explicar outros fenômenos.

A elevação da temperatura que ocorre nos condutores das correntes elétricas deve ocorrer também no globo terrestre. Não seria esta a causa do calor interno constatado recentemente pelas experiências relatadas, em uma das últimas sessões da Academia, por um de seus membros cujos trabalhos sobre o calor fizeram esta parte da Física entrar no domínio das matemáticas? E quando nós verificamos que esta elevação de temperatura produz, no caso de uma corrente muito energética, uma incandescência permanente, acompanhada da mais viva luz, sem combustão nem perda de substância, nós não poderíamos concluir que os globos opacos só são assim por causa da pouca energia das correntes elétricas que se estabelecem nele, e achar nas correntes mais ativas a causa do calor e da luz dos globos que brilham por eles mesmos? (AMPÈRE, 1820/1885, p. 57, tradução nossa)

É interessante notar como a ideia de correntes elétricas no interior da Terra se apresenta clara a Ampère e como ela lhe possibilita explicar uma diversidade grande de fenômenos. Ele finaliza sua leitura, que será retomada na sessão seguinte da academia, considerando que esse mesmo princípio que explica a magnetização da Terra deve ser a causa da magnetização dos ímãs.

Agora, se as correntes elétricas são a causa da ação diretiva da terra, as correntes elétricas serão também a causa daquelas de um ímã sobre outro ímã, de onde se segue que um ímã deve ser considerado como um 
conjunto de correntes elétricas que ocorrem nos planos perpendiculares a seu eixo, dirigidas de maneira que o polo austral, que se coloca do lado do norte, encontra-se à direita de suas correntes, pois ela está sempre à esquerda de uma corrente colocada fora do ímã, e que faz face na direção paralela, ou, mais ainda, essas correntes se estabelecem de início no ímã, seguindo as curvas fechadas as mais curtas, seja da esquerda à direita, seja da direta à esquerda, e então a linha perpendicular aos planos dessas correntes tornam-se o eixo do ímã, e suas extremidades tornam-se os polos. Assim, a cada um dos polos de um ímã, as correntes elétricas que o compõem são dirigidas seguindo curvas fechadas concêntricas. Eu imitei esta disposição à medida que ela era possível com uma corrente elétrica, enrolando o fio condutor em espiral, esta espiral era formada com um fio de latão e terminada por duas porções retilíneas desse mesmo fio, que estavam fechadas em dois tubos de vidro, afim que elas não se comunicassem e pudessem ser ligadas às duas extremidades da pilha. (AMPÈRE, 1820/1885, p. 57-58, tradução nossa)

O mais marcante desse trabalho de Ampère é ele não ter partido dos dados que ele dizia obter. Quando o autor apresenta esse texto, ele não havia realizado as experiências que declara. Ele concebe uma ideia muito nova e a desenvolve com base em razões físicas e, também, metafísicas. Sua concepção de unidade entre os fenômenos é o principal motor de sua criação.

\section{Considerações finais}

Inicialmente, este capítulo apresentou uma corrente filosófica que atribui grande peso aos fatos e observações na 
elaboração do conhecimento científico. As concepções empírico-indutivistas consideram a possibilidade de se elaborar leis e teorias a partir de uma análise sistemática dos dados, na qual a correta organização dos mesmos permite a consolidação do conhecimento.

Consideramos que a análise histórica de um episódio da ciência não tem a função de afirmar ou refutar uma determinada corrente filosófica. Talvez a maneira mais delicada de relacionar história e filosofia da ciência seja através da tentativa de problematizar visões sobre o conhecimento, buscando uma postura reflexiva e crítica sobre ambas.

Retomando os casos históricos aqui apresentados, vemos que uma experiência e as informações obtidas por meio dela são fundamentais para a elaboração da ciência. Assim, podemos afirmar que a eletrodinâmica foi desenvolvida com forte apelo empírico. Contudo, não podemos Ihe superestimar, como se um experimento nos permitisse desvelar a realidade por completo. Isto é, devemos ter cuidado com o uso da palavra "descoberta", pois esta nos leva, muitas vezes, a refletir que os conceitos que utilizamos para pensar o mundo estão prontos, esperando apenas "serem encontrados".

Verificar que a experiência de Oersted foi interpretada por no mínimo três formas bastante distintas é algo que nos permite pensar sobre o quanto um dado é objetivo. Podemos considerar que, em alguma medida, as observações são carregas de teoria, utilizando esse termo de modo livre. O que vemos acaba sendo influenciado pelo que acreditamos existir, visto que esses pressupostos ontológicos podem ter origens diversas.

Tanto Oersted quanto Ampère buscava uma unidade fundamental para a natureza. Contudo, seus pensamentos foram levados a caminho muito diferentes. Enquanto o primeiro 
buscou apoio em visões mecanicistas que consideravam a existência de fluídos, o segundo procurou uma unidade fundamental que permitisse uma elaboração matemática para interações, propondo a existência de correntes elétricas em diferentes corpos.

A interpretação do mundo envolve um complexo processo, por meio do qual diferentes elementos de nossas bagagens culturais se entrecruzam. E, ao ensinarmos ciências, precisamos estar constantemente vigilantes sobre esse processo, pois, somente assim, como professores, seremos capazes de dialogar com nossos alunos, valorizando suas dúvidas e permitindo a construção de novos olhares sobre a natureza.

\section{Referências}

AMPÈRE, André-Marie. Introduction du Mémoire Inédit et Inachavé sur l'Electricité et le Magnetisme de 1801. In: BLONDEL, Christine. A-M Ampère et la Création de l'Electrodynamique (1820-1827). BNF: Paris, 1982.

De l'Action Exercée sur un Courant Électrique par un Autre Courant, Le Globe Terrestre ou un Aimant. In : SOCIETÉ FRANCAISE DE PHYSIQUE. Collection de Mémoires Relatifs a la Physique - Tome II. Gauthier-Villars: Paris, 1820/1885. p. 7-54.

Recueil d'Observations Electrodynamiques. GauthierVillars: Paris, 1822/1885.

Figure "Le bonhomme d'Ampère" In : AMPÈRE L'HISTOIRE DE L'ÉLECTRICITÉ, 1820/2005. Disponível em: <http://www.ampere.cnrs.fr/manuscrits/avoir/avoir-electro. php\#bonhomme>. Acesso em: 5 jul. 2016. 
AUDOUZE, Jean. Moi, Benjamin Franklin. Dunod: Paris, 2006.

BLONDEL, Christine. A-M Ampère et la Création de I'Electrodynamique (1820-1827). BNF: Paris, 1982.

GIL-PÉREZ, Daniel; MONTORO, Isabel Fernández; ALÃ, Jaime Carrascosa; CACHAPUZ, António; PRAIA, João. Para uma Imagem não Deformada do Trabalho Científico. Ciência \& Educação, v. 7, n. 2, p. 125-153, 2001.

GURGEL, Ivã. Elementos para uma Poética das Ciências: Fundamentos Teóricos e Implicações ao Ensino. 2010. 301 f. Tese (Doutorado em Educação) - Faculdade de Educação, Universidade de São Paulo, São Paulo, 2010. Disponível em: <http://www.teses.usp.br/teses/disponiveis/48/48134/ tde-09092010-105921/en.php>. Acesso em: 5 jul. 2016.

HANSON, Norwood Russell. Observação e Interpretação. In: MORGENBESSER, Sidney (Org.). Filosofia da Ciência. Tradução de Leônidas Hergenberg; Octany Silveira da Mota. Cultrix: São Paulo, 1974, p. 127-141.

HÁÜY, René. Traite Élémentaire de Physique. Adolphe Delahays: Paris, 1821/1855.

HOFMANN, James. André-Marie Ampère. Blackwell Publishers: Boston, 1995.

LOCQUENEUX, Robert. Ampère: Encyclopédiste et Métaphysicien. EDP Sciences: Lille, 2008.

MARTINS, Roberto de Andrade. Oersted e a descoberta do eletromagnetismo. Cadernos de História e Filosofia da Ciência, v. 10, p. 89-114, 1986. 
MILL, Jonh Stuart. Sistema de Lógica Indutiva e Dedutiva. Abril Cultural: São Paulo, 1843/1978.

OERSTED, Hans Christian. Experiências sobre o efeito do Conflito Elétrico sobre a Agulha Imantada. Cadernos de História e Filosofia da Ciência, v. 10, p. 115-122, 1820/1986.

ZANETIC, João; MOZENA, Erika Regina. Evolução dos Conceitos da Física. São Paulo: IFUSP, 2012. 